\title{
El uso de humidificación en niños con croup no mostró beneficios
}

COMMIT collaborative group. Lancet. 2005 Nov 5; 366:1607-1621.

\section{Objetivo}

Determinar si el nivel de humidificación de la nebulización influye en la evolución del croup moderado a severo en niños que ingresan al departamento de emergencias.

\section{Diseño}

Ensayo clínico aleatorizado simple ciego, realizado entre el 2001 y el 2004 en un centro de emergencias pediátricas de tercer nivel.

Lugar

The Hospital for Sick Children, y Universidad de Toronto, Canadá

\section{Pacientes}

Se incorporaron al estudio 140 niños previamente sanos de 3 meses a 10 años de edad con 1, 2 o más puntos según el puntaje de Westley para croup (el puntaje varía de 0 a 17 y evalúa estridor, retracción inter y subcostal, entrada de aire en los pulmones, cianosis y nivel de conciencia).

\section{Intervención}

Se aleatorizaron los pacientes para que recibir una de las tres intervenciones: treinta minutos usando la técnica de niebla de nebulizador (técnica placebo, o la usada habitualmente, $n=48$ ), nebulización con liberación controlada de humedad al $40 \%$ (placebo usado óptimamente, $n=46$ ) y nebulización con liberación controlada de humedad al $100 \%(n=46)$, con partículas de agua de $6,21 \mu \mathrm{m}$ de diámetro.

\section{Medición de resultados principales}

El resultado se definió a partir de los cambios observados a los 30 y 60 minutos en el puntaje de Westley para croup, a partir de la medición previa al tratamiento asignado en los tres grupos.

\section{Resultados Principales}

No hubo diferencias significativas entre los grupos. A los 30 minutos la diferencia en mejoría del puntaje de croup entre el grupo de niebla y el grupo de humedad al $40 \%$ fue de 0,03 (IC95\% - 0,72 a 0,66 ), entre humedad al 40 y $100 \%, 0,16$ (IC $95 \%-0,86$ a 0,53 ) y entre niebla y humidificación al $100 \%$ fue de 0,19 (IC 95\%, - 0,8 a 0,49 ). Los resultados a los 60 minutos fueron similares en los tres grupos, así como las diferencias de frecuencia cardiaca, respiratoria y saturación de oxígeno. La tasa de excelentes respondedores, los que terminaron con puntaje de croup en 0 , los que buscaron atención médica luego de la intervención, y los que fueron internados o se les dió tratamiento farmacológico luego del estudio fueron similares en los tres grupos. En ningún paciente fue necesario utilizar adrenalina, dexametasona o internación durante el desarrollo del estudio.

Tabla 1: Resultados clínicos luego del estudio

\begin{tabular}{|c|c|c|c|}
\hline & $\begin{array}{c}\text { Nebulización con } \\
\text { niebla ( } n=48 \text { ) }\end{array}$ & $\begin{array}{l}\text { Humidificación al } \\
40 \%(n=46)\end{array}$ & $\begin{array}{l}\text { Humidificación al } \\
100 \% \quad(n=46)\end{array}$ \\
\hline Internación & $1(2,1 \%)$ & $2(4,3 \%)$ & 0 \\
\hline Excelentes Respondedores & $14(29,2 \%)$ & $12(26,1 \%)$ & $18(39,1 \%)$ \\
\hline $\begin{array}{l}\text { Puntaje de Westley de } 0 \text { al } \\
\text { final del estudio }\end{array}$ & $9(18,8 \%)$ & $6(14 \%)$ & $8(18,6 \%)$ \\
\hline Dexametasona tras el & $43(91,5 \%)$ & $39(86,7 \%)$ & $38(82,6 \%)$ \\
\hline estudio & $4(8,3 \%)$ & $4(8,7 \%)$ & $4(8,7 \%)$ \\
\hline $\begin{array}{l}\text { Adrenalina tras el esfudio } \\
\text { Volvieron pára atencion }\end{array}$ & $9(19 \%)$ & $16(35 \%)$ & $9(20 \%)$ \\
\hline
\end{tabular}

\section{Conclusiones}

La utilización de humidificación al 100\% con partículas de un tamaño que específicamente se depositan en la laringe no pudo demostrar mejoría al compararla con humidificación al 40\% o humidificación por medio de niebla en niños con croup moderado a severo tratados en un servicio de emergencias pediátricas.

Fuente de financiamiento: Subsidio de "Physicians' Services Incorporated Foundation of Ontario"

\section{Comentario}

Una causa frecuente de obstrucción e inflamación de la vía aérea alta en niños es el croup viral. El curso de la enfermedad es benigno y en muchos casos autolimitado. La terapia de humidificación puede tener complicaciones como quemaduras, alteraciones pulmonares, disquinesia ciliar, broncoespasmo en niños sibilantes, o hiponatremia en neonatos. Por estos motivos se planteó determinar si este tratamiento tiene los suficientes efectos positivos como para mantenerlo. Las bases del tratamiento actualmente son los corticosteroides, incluso en monodosis por via oral ${ }^{1,2}$ y la adrenalina nebulizada ${ }^{3}$, pero no hay que olvidar el efecto tranquilizador de estar cerca de los padres o la baja temperatura de algunos aparatos humidificadores.

Ningún estudio hasta el momento pudo demostrar que el aire humidificado tenga valor ${ }^{1,2}$; el fundamento de este tratamiento es que la humidificación puede disminuir la sequedad e inflamación de las mucosas y la viscosidad de las secreciones. Se tuvo en cuen- ta el tamaño de las partículas aerosolizadas; el grupo de humidificación al $100 \%$ recibió partículas que por su tamaño $(5-10 \mu \mathrm{m})$ tienen la mayor probabilidad de depositarse en la laringe. Esta investigación demostró que la humidificación al $100 \%$ no dió mejores resultados que el grupo con humidificación al $40 \%$, a pesar de usar un tamaño óptimo de partículas y adecuadas condiciones de temperatura, flujo de gas y concentración de oxigeno.

\section{Conclusiones del comentador}

Esta patología puede ser lo suficientemente grave como para requerir antinflamatorios con o sin agentes vasoconstrictores para mejorar la clínica, y es poco probable que sea afectada por la terapia de humidificación.

Jorge Kontos [ Medico de Familia. Equipo de Salud Familiar. Córdoba, Capital. ]

Kontos JA. El uso de humidificación en niños con croup no mostró beneficios. Evid. actual. práct. ambul. 2006;9(5):139 Sep - Oct. 206. Comentado de: Controlled delivery of high vs low humidity vs mist therapy for croup in emergency departments. Scolnik D, Coates AL, Stephens D. JAMA, 2006; 295:1274-1280. PMID: 16537737

\section{Referencias}

1. Fernandez S. Una monodosis de dexametasona oral demostro ser útil en el croup leve. Evid. Actual. Práct. Ambul. 2005;8:8. Comentado de: A randomized trial of a single dose of oral dexamethasone for mild croup. Bjornston CL, Klassen TP, Williamson J, el al. For the Pediatric Emergency Research Canada Network. N Engl J Med 2004;351:1306-13. PMID 15385657

2. Rizos JD; DiGravio BE; Sehl MJ; Tallon JM. The disposition of children with croup treated with racemic epinephrine and dexamethasone in the emergency department. J Emerg Med 1998 Jul-Aug;16(4):535-9.

3. Lenney W; Milner AD. Treatment of acute viral croup. Arch Dis Child 1978 Sep;53(9):704-6

4. Bourchier D; Dawson KP; Fergusson DM. Humidification in viral croup: a controlled trial. Aust Paediatr J 1984 Nov;20(4):289-91. 